UDC 316.42

LBC 60.524

\title{
RELIGIOUS FACTOR IN THE IMPLEMENTATION OF THE UN NEW URBAN AGENDA
}

\author{
Elena M. Miroshnikova \\ Leningrad State University named after A.S. Pushkin, Saint Petersburg, Russian Federation
}

\begin{abstract}
The article discusses the importance of taking into account the religious factor in the implementation of sustainable development plans for modern cities based on the analysis of the UN integrated program New Urban Agenda. Urbanization is one of the challenges that is significantly changing the geopolitical and religious landscape. The multi-million-strong concentration of people with different worldviews and cultural traditions in a megalopolis creates a lot of technological and humanitarian problems not only for a particular country, but for the world as a whole. In this regard, the role of large cities as global policy actors is increasing. The UN developed a comprehensive program New Urban Agenda (2016), which is aimed at the sustainable development of the modern city. This program ignores the role of the religious factor in solving socio-economic and humanitarian problems caused by growing urbanization. Despite the crisis state of some religions in various parts of the world, the number of people who engage in religious activities is growing, and today there are 84 per cent of such people. The social activities of various religious organizations are respected, and they make a significant contribution to the sustainable development of the modern city. The role of religious organizations at the local level is particularly significant. It is necessary to mention the ambivalent role of religion, namely, the manifestations of its disintegrating function: intolerance of other beliefs, refusal to observe the secular norms of the community, extremist appeals and terrorist acts under religious slogans. Addressing the issue of the public role of religion and the use and interpretation of religious symbols is one of the problems of sustainable urban development. The idea of just and peaceful coexistence in a modern city cannot be realized without a constructive dialogue between state, public and religious organizations. Of particular interest is the Rabat Plan (2017) by religious organizations to promote the implementation of the New Urban Agenda. Religious organizations can make a constructive contribution to economic progress not only by making substantial financial contributions, but also by demonstrating the practical implementation of the moral values of mutual understanding and respect.
\end{abstract}

Key words: urbanization, sustainability, faith-based organizations, common good, religious freedom, religious pluralism, tolerance, restrictions.

УДК 316.42

ББК 60.524

\section{РЕЛИГИОЗНЫЙ ФАКТОР \\ В РЕАЛИЗАЦИИ НОВОЙ ПОВЕСТКИ ГОРОДСКОГО РАЗВИТИЯ ООН (NEW URBAN AGENDA)}

\author{
Елена Михайловна Мирошникова \\ Ленинградский государственный университет им. А.С. Пушкина, \\ г. Санкт-Петербург, Российская Федерация
}

Аннотация. На основе анализа комплексной программы ООН «Новая повестка городского развития» (New Urban Agenda) в статье показана важность учета религиозного фактора при реализации планов устойчивого развития современных городов. Урбанизация является одним из вызовов, существенно меняющим геополитический и религиозный ландшафт. Многомиллионная концентрация людей в мегаполисе с разными мировоззренческими взглядами и культурными традициями порождает массу проблем как технологического, 
так и гуманитарного характера не только для конкретной страны, но в целом для мира. В связи с этим возрастает роль крупных городов как акторов глобальной политики. В 2016 г. ООН разработала комплексную программу «Новая повестка городского развития» (New Urban Agenda), которая предусматривает устойчивое развитие разнообразных сфер жизни современного города. Между тем данная программа обходит молчанием роль религиозного фактора в решении социально-экономических и гуманитарных проблем, вызванных растущей урбанизацией. Несмотря на кризисное состояние определенных религий в тех или иных частях света, в целом в мире количество людей, конфессионально ангажированных, растет и составляет на сегодняшний день 84 \%. Помимо этого вызывает уважение социальная деятельность самых различных религиозных организаций, вносящая существенный вклад в устойчивое развитие современного города. Особенно значительна роль религиозных организаций на местном уровне. Однако нельзя не сказать об амбивалентной роли религии, а именно о проявлениях ее дезинтегрирующей функции: нетерпимость к другим верованиям, отказ от соблюдения светских норм общежития, экстремистские призывы и террористические акты под религиозными лозунгами. Решение вопроса публичной роли религии, использования и трактовки религиозных символов, в частности, в современном городе, представляет собой одну из проблем на пути устойчивого городского развития. Без конструктивного диалога государственных, общественных и религиозных организаций воплотить идеи справедливого и мирного сосуществования в современном городе не представляется возможным. В этом отношении особый интерес представляет программа, разработанная в 2017 г. религиозными организациями по содействию реализации Новой повестки городского развития $\mathrm{OOH}$ «Рабат-План». Религиозные организации могут внести свой конструктивный вклад в экономический прогресс не только существенными финансовыми взносами, но прежде всего примером практического воплощения моральных ценностей взаимопонимания и уважения.

Ключевые слова: урбанизация, устойчивость, религиозные и мировоззренческие организации, всеобщее благо, религиозная свобода, религиозный плюрализм, толерантность, ограничения.

\section{Введение}

Урбанизация приобретает характер одного из самых значительных по масштабам и глубине преобразований в XXI веке. В настоящее время $54 \%$ мирового населения проживает в городах, к 2050 г. ожидается его увеличение до 66 \% [The World Population... web]. Список крупнейших городов возглавляет японская столица Токио (почти 38 млн), затем следуют Дели, Шанхай, Мехико, Сан Пауло, Мумбаи. Согласно данным ООН «World Urbanization Prospects», 90 \% роста городского населения приходятся на Азию и Африку, прежде всего на такие страны, как Индия, Китай, Нигерия. Городское население в этих государствах к 2050 г. увеличится на 404 млн, 292 млн и 212 млн чел., соответственно [World's Population... web]. Крупные города становятся движущей силой глобальной политики, поскольку в них в большей степени концентрируются социально-экономические, технологические, культурные и экологические процессы. Климатический саммит $\mathrm{OOH}$ в сентябре 2019 г. особенно показателен в этом отношении. 16-летняя шведская активистка Грета Тунберг обвинила мировых лидеров в пустословии, в их стремлении к вечному экономическому росту и прибыли на фоне разрушения целых экосистем, в лишении подрастающего поколения будущего. Генеральный секретарь ООН Антониу Гуттериш призвал руководителей государств представить конкретные планы по сокращению вредных выбросов парниковых газов и стратегии полного прекращения выбросов к 2050 году. Незадолго до начала работы саммита Китай, являющийся крупнейшим производителем парниковых газов (27 \% мировых выбросов) и одним из основных лидеров роста городского населения, ратифицировал Парижское соглашениепо борьбе с изменением климата, которое было принято в декабре 2015 г. в рамках конвенции $\mathrm{OOH}$ об изменении климата. Россия также ратифицировала этот важный международный документ, который будет регулировать с 2020 г. снижение выбросов углекислого газа в атмосферу [UN Climate Action... web].

\section{Остановка проблемы}

Достойным ответом на вызовы современности можно считать Новую повестку городского развития $\mathrm{OOH}$ (New Urban Agenda - NUA) 2016 года. Рассчитанная на 20 лет NUA направлена на то, чтобы урбанизация стала сильным средством устойчивой модернизации как развитых, так и развивающихся стран. В целях обес- 


\section{НАУЧНЫЕ СООБЩЕНИЯ}

печения плюрализма и мирного сосуществования в рамках все более неоднородных и поликультурных обществ предлагается «приветствовать разнообразие в городах... укреплять социальную сплоченность, межкультурный диалог, взаимопонимание, терпимость и взаимоуважение, гендерное равенство, инновации, предпринимательство, всеохватность самобытность, безопасность и достоинство всех людей...» [The New Urban... web]. Ключевым понятием NUA является устойчивость в самых разнообразных сферах городского развития: жилье, основные услуги, продовольственная безопасность, здравоохранение, образование, достойная работа, природные ресурсы. Под устойчивым развитием понимается такая его модель, которая нацелена на соблюдение баланса между решением социальных, экономических проблем и сохранением окружающей среды.

Речь идет не только о планировании и развитии собственно городской инфраструктуры, включая парки, площади, архитектуру и т. п., но и об обеспечении необходимых условий равного доступа жителей городов ко всеобщему благу. Концепция стратегии NUA ocнована на признании всеобщности принципов справедливости, мира, рационального экологического пользования ресурсами, неразрывной взаимосвязи человека и природы, ответственности перед будущими поколениями.

Анализ документа «New Urban Agenda NUA» показал, что в нем отсутствует какаялибо рефлексия в отношении религиозного фактора, его существенного влияния на современную городскую жизнь.

\section{Амбивалентная роль религии в обществе}

Было бы наивно предполагать, что соответствующие структуры ООН не признают значимость религии в мире в целом и в сфере урбанизации в частности, в то время как 84 \% населения мира считают себя верующими, а религиозный ландшафт городов претерпевает серьезнейшие изменения на фоне демографических и миграционных вызовов. Самой растущей религиозной группой в мире являются мусульмане. По данным исследований изменения глобального религиозного ландшафта, с 2035 г. количество детей, рожден- ных от мусульман, начнет превышать число новорожденных у христиан, а в период между 2055 и 2060 гг. семеро из десяти младенцев будут рождены или от мусульман (36 \%), или от христиан (35\%) и только $9 \%$ детей будет у конфессионально неангажированных родителей [The Changing Global... web].

Видимо, причина, по которой NUA обходит молчанием роль религиозного фактора, кроется в амбивалентности религии как социального феномена и далеко не бесспорной теории политкорректности. К сожалению, в настоящее время в мире отсутствует универсальное понимание соотношения религиозной свободы и толерантности, что подтверждается в одном из выступлений Хайнера Билефельдта, назначенного Специальным докладчиком $\mathrm{OOH} \mathrm{по} \mathrm{свободе} \mathrm{религии} \mathrm{или} \mathrm{убеждений} \mathrm{в}$ 2010 г. и в течение последующих шести лет представлявшего ежегодные отчеты о состоянии религиозной свободы в мире. «Религиозная свобода - это право свободы, а не право защиты чести религий, причем определенных религий. Тут бесконечно много возникает недоразумений... Религиозная свобода требует гораздо большей ясности, чем семантика толерантности. Государство как гарант прав человека должно создавать пространство для свободы всех и в том числе для равной свободы всех в вопросах религии и мировоззрения, то есть это касается не только индивидов, но и сообществ, а также инфраструктурных компонентов» [Bielefeld web].

В этом отношении важно упомянуть о плане действий, посвященном борьбе с проявлениями национальной, расовой и религиозной ненависти, который был разработан соответствующими структурами ООН в 2012 году. Этот документ получил название «РабатПлан», так как был принят во время заседания в марокканской столице. Одним из важнейших пунктов принятых рекомендаций является заключение о том, чтобы государства, в законодательстве которых имеются законы о богохульстве, их отменили, поскольку подобные законы негативно сказываются на свободе религии или убеждений и на возможности здорового диалога или дискуссий [The Rabat Plan... web].

Между тем существует и другая сторона медали амбивалентной роли религии в об- 
ществе, а именно проявления ее дезинтегрирующей функции. Например, нетерпимость к представителям другого вероисповедания, претензии наиболее распространенных в той или иной стране религий на приоритетное положение. К сожалению, растет число жертв в результате террористических актов, совершенных под религиозными лозунгами. Одним из последних событий в этом печальном перечне стало убийство 40 мусульман, в большинстве своем мигрантов, в двух мечетях новозеландского города Крайстчерч. Действительно, миграционный взрыв является серьезным вызовом современному миру, особенно в Европе. Но Новая Зеландия вовсе не значилась в списке горячих точек. В стране с населением почти 5 млн мусульмане составляют всего 1 \%. Для Новой Зеландии характерен один из самых низких уровней государственных ограничений в отношении религии в мире. В 2016 г. он составлял 0,48 балла из 10 возможных по индексу государственных ограничений Pew Research Center's (GRI). Кроме того, страна имеет «низкий» уровень социальной напряженности в отношении к религии согласно индексу социальных конфликтов $(0,9$ из 10) [Kishi et al. web].

Получается, что в глобальном мире невозможно решать проблему автономно, взаимозависимость социально-экономического и гуманитарного развития усугубляется глубиной демографических и миграционных вызовов, осложняя проблему мирного сосуществования людей с различными привычками, традициями, обрядами, в том числе и религиозными.

Тема доступности и законности религиозных обрядов в современном городе стремительно актуализируется в последние десятилетия, высвечивая серьезнейшие диспропорции в праве людей на религиозную свободу и собственно публичной роли религии и неприятие гражданами по религиозным мотивам определенных светских нормативов. Например, в Дании известны случаи отказа от рукопожатия во время церемонии вручения документов о гражданстве. В этой стране с недавнего времени запрещено появляться в хиджабе в публичных местах. В противном случае взимается штраф 140 евро. В 2010 г. Национальная Ассамблея Франции приняла акт, зап- рещающий людям скрывать свои лица в публичных местах. Нарушители обязаны заплатить штраф в размере 150 евро и посещать обязательные занятия по французскому гражданству. Тот, кто принуждает женщину носить религиозную одежду, наказывается двухлетним тюремным сроком и штрафом в 60000 евро. В 2014 и 2017 гг. Европейский суд по правам человека в ответ на жалобу мусульманок, желавших носить бурку как выражение их права на религиозную свободу, оставил французский закон в силе.

\section{Религиозный фактор и устойчивое городское развитие}

Особое место в устойчивом характере развития города отводится государственным школам и непосредственно решению проблемы наличия в них религиозных символов. Франция, Бельгия, Австрия, Голландия, Болгария приняли законы, запрещающие религиозную одежду в школах. В Великобритании такого запрета нет, но тем более показателен прецедент с обращением в суд матери мусульманки с жалобой о дискриминации. Так расценила мать отказ руководства одной из лучших школ Лондона Holland Park School посещать занятия в хиджабе ее одиннадцатилетней дочери [Taylor web].

Тема наличия религиозных символов в государственных школах нашла свое неожиданное продолжение в Германии. В 1995 г. там состоялся судебный процесс о наличии распятия в классных комнатах баварских школ. В результате наличие образа Христа, распятого на кресте, было признано культурным символом и в земле Бавария школьный процесс не претерпел изменений. Тем не менее спустя почти двадцать лет именно этот прецедент стал одним из аргументов обращения в суд группы мусульман об отмене запрета на ношение хиджаба для судей, поскольку, по мнению истцов, хиджаб является символом культуры и, кроме того, этот запрет является формой дискриминации женщин. Конституционный суд Баварии подтвердил законность запрета, объявив, что дело о распятии имеет совсем другую природу и не ставит под сомнение нейтралитет конкретного судьи или юриста. Суд решил, что это также не являет- 
ся дискриминацией в отношении женщин, так как ношение религиозных символов запрещено и в отношении мужчин [Germany: Bavarian Court... web].

Проблема бесконфликтного межконфессионального взаимодействия особенно актуальна для мегаполисов, притягивающих к себе огромные массы людей различных этносов и религий. Очевидно, что религия не может быть отодвинута в сферу приватности. Религиозные общины представляют собой значительную силу на местном, национальном и международном уровнях, выступая в роли моста между жителями и органами власти. Между тем, на мой взгляд, устойчивость городского развития существенно бы укрепилась, если бы религиозные организации наводили мосты прежде всего между собою, а не концентрировались на борьбу с секуляризмом. Активное участие религиозных организаций в разнообразных сферах жизнедеятельности современного города способствует устойчивому характеру его развития. Надо отдать должное социальной работе религиозных организаций в становлении устойчивого и справедливого развития в современном мире. Среди самых разнообразных форм особое место занимают центры для бездомных, природоохранные инициативы, образовательные, спортивные, молодежные программы. В настоящее время наиболее злободневной является проблема помощи беженцам и мигрантам. По данным ООН, лишь в течение одного 2017 г. 68 млн людей вынуждены были покинуть свои дома. Чтобы лучше осознать масштабы этого явления, можно представить, что каждую минуту 28 человек в мире вынуждены перемещаться [Global Trends... web].

Ярким примером активного включения религиозных организаций в решение проблемы устойчивого городского развития является, например, деятельность католической церкви в ФРГ. В 2016 г. 27 диацезов собрали 127,7 млн евро для помощи беженцам. При этом 53,4 млн евро направлены на поддержку соответствующих проектов внутри церкви и 74,3 млн переданы в кризисные регионы. Объемы столь внушительной финансовой поддержки не уменьшаются, а, напротив, растут. Например, в 2015 г. было собрано 112 млн евро [Katholische Kirche in... web]. Приведенные данные убедительно свидетельствуют о реальных возможностях религиозных общин внести свой весомый вклад в справедливое и устойчивое развитие городов. Несомненно, их усилия принесут больше положительных результатов при вовлечении религиозных организаций в качестве акторов в городское планирование и политику. Особенно это будет эффективно на локальном уровне, где лидеры общин тесно взаимодействуют с местными органами власти.

О необходимости активного участия религиозных организаций в реализации Новой повестки городского развития $\mathrm{OOH}$ (New Urban Agenda - NUA) было заявлено в ноябpe 2017 г. в Сингапуре в ходе первого в истории Всемирной Городской Кампании (World Urban Campaign) совместного заседания Urban Thinkers Campus с представителями различных религиозных организаций [Ives, Van Eymeren web]. В результате обсуждения темы «Город, который нам нужен» была принята программа религиозного участия в Новой повестке городского развития (Faith Based Engagement of the New Urban Agenda) [Faith Based Engagement... web]. Одним из конкретных предложений стало создание Международного религиозного совета по урбанизации (IRCU), призванного на национальном и международном уровнях решать проблемы общего блага в рамках Новой повестки городского развития. Согласно «Faith Based Engagement of the New Urban Agenda», религиозная вера способна помочь в строительстве современных городов, решая общие социальные и экономические проблемы. Изучение взаимосвязей между урбанизацией, культурой и инновациями является базисом для достижения безопасного и устойчивого городского развития. «Города возможностей: Объединяя культуру и инновации» - такой теме посвящен следующий мировой урбанистический форум в АбуДаби в феврале 2020 года.

\section{Заключение}

Устойчивость городского развития в немалой степени зависит от решения проблемы публичного присутствия религии, поскольку публичность - это составная часть религиозной свободы. Однако планирование городской 
политики должно учитывать тот факт, что предоставление равного доступа ко всеобщим благам не означает уравнительного распределения благ. Следовательно, необходимы законодательно обоснованные определенные ограничения по отношению к публичному выражению религии. Например, все более актуальной становится защита музейных экспонатов, художественных выставок, театральных постановок, составляющих важную часть культурной жизни современного города, от неправомерных действий под предлогом защиты религиозных чувств.

Реализация Новой повестки городского развития $\mathrm{OOH}$ (NUA), в которой будет учтен религиозный фактор, способна принять превентивные меры по преодолению возможных конфликтов на религиозной почве. В современном глобальном мире невозможно отгородиться и замкнуться в отдельно взятом регионе. Отсутствие единой четкой стратегии в миграционной политике, практика ложной политкорректности по отношению, например, к нарушениям со стороны мигрантов в других странах, отсутствие эффективного ответа на вызовы религиозного многообразия являются серьезным препятствием на пути устойчивого городского развития согласно целям Новой повестки $\mathrm{OOH}$.

\section{СПИСОК ЛИТЕРАТУРЫ}

Bielefeld web - Bielefeld $H$. Religionsfreiheit ist kein Schutzrecht der Ehre [Archiv 10.07.2016] // https://www.deutschlandfunkkultur.de/ theologe-heiner-bielefeldt-religionsfreiheitist-kein.1278.de.html?dram:article_id=359692.

Faith Based Engagement... web - Faith Based Engagement and Implementation of the New Urban Agenda // http://www.worldurbancampaign.org/ events/faith-based-engagement-andimplementation-new-urban-agenda.

Germany: Bavarian Court... web-Germany: Bavarian Court Upholds Headscarf Ban for Judges, Prosecutors [Deutsche Welle 18.03.2019] // https://www.dw.com/en/germany-bavariancourt-upholds-headscarf-ban-for-judgesprosecutors/a-47960676.

Global Trends... web - Global Trends Forced Displacement in 2017 [United Nations High
Commissioner for Refugees]// https:// www.unhcr.org/en-us/statistics/unhcrstats/ 5b27be547/unhcr-global-trends-2017.html.

Ives, van Eymeren web - Ives C., van Eymeren A. Religious Faith Can Help People to Build Better Cities - Here's How [The Conversation 11.12.2017] // http://theconversation.com/ religious-faith-can-help-people-to-build-bettercities-heres-how-88426.

Katholische Kirche in... web-Katholische Kirche in Deutschland. Zahlen und fakten 2016/2017. Juli $2017 / /$ https://www.dbk.de/fileadmin/redaktion/ Zahlen\%20und\%20Fakten/Kirchliche\%20 Statistik/Allgemein - Zahlen und Fakten/ AH294_Zahlen-und-Fakten-2016-2017 web.pdf.

Kishi et al. web - Kishi K., Kramer S., Marshall J., Sandstrom A. 4 Facts About Religion in New Zealand [Pew Research Center 21.03.2019]//https:/ /www.pewresearch.org/fact-tank/2019/03/21/4facts-about-religion-in-new-zealand.

Taylor web-Taylor D. Muslim Mother Takes Legal Action Against School over Face Veil Ban [The Guardian. 21.07.2017] // https://www.theguardian.com /world/2017/jul/20/muslim-mother-takes-legalaction-against-school-over-face-veil-ban.

The Changing Global... web - The Changing Global Religious Landscape [Pew Research Center, April 5, 2017, The Changing Global Religious Landscape]// https://www.pewforum.org/2017/ 04/05/the-changing-global-religious-landscape.

The New Urban... web - The New Urban Agenda [The New Urban Agenda. Habitat III. The United Nations Conference on Housing and Sustainable Urban Development. 20.10.2016] // http://habitat3.org/the-new-urban-agenda.

The Rabat Plan... web-The Rabat Plan: Challenging Hatred while Preserving Free Expression [IIMA Human Rights Office. 05.03.2013] // http:// www.iimageneva.org/the-rabat-plan-challenginghatred-while.

The World Population... web - The World Population Prospects: 2015 Revision // https://www.un.org/ en/development/desa/publications/worldpopulation-prospects-2015-revision.html.

UN Climate Action... web-UNClimate Action Summit 2019 [United Nations 23.09.2019] // https:// www.un.org/en/climatechange/un-climatesummit-2019.shtml.

World's Population... web - World's Population Increasingly Urban with More than Half Living in Urban Areas [UN Search. 10.07.2014] // https:// www.un.org/en/development/desa/news/ population/world-urbanization-prospects.html. 


\section{REFERENCES}

Bielefeld H., 2016. Religionsfreiheit ist kein Schutzrecht der Ehre. URL: https:// www.deutschlandfunkkultur.de/theologeheiner-bielefeldt-religionsfreiheit-ist.kein.1278. de.html?dram:article_id=359692.

Faith Based Engagement and Implementation of the New Urban Agenda. URL: http://www.world urbancampaign.org/events/faith-basedengagement-and-implementation-new-urbanagenda.

Germany: Bavarian Court Upholds Headscarf Ban for Judges, Prosecutors. 2019. Deutsche Welle 18.03.2019. URL: https://www.dw.com/en/ germany-bavarian-court-upholds-headscarfban-for-judges-prosecutors/a-47960676.

Global Trends Forced Displacement in 2017. United Nations High Commissioner for Refugees. URL: https://www.unhcr.org/en-us/statistics/ unhcrstats/5b27be547/unhcr-global-trends2017.html.

Ives C., Van Eymeren A. 2017. Religious Faith Can Help People to Build Better Cities - Here's How. The Conversation 11.12.2017. URL: http:// theconversation.com/religious-faith-can-helppeople-to-build-better-cities-heres-how-88426.

Katholische Kirche in Deutschland. Zahlen und fakten 2016/2017. Juli 2017. URL: https:// www.dbk.de/fileadmin/redaktion/Zahlen \% 20und\%20Fakten/Kirchliche\%20Statistik/ Allgemein___Zahlen_und_Fakten/AH294 Zahlen-und-Fakten-2016-2017_web.pdf.

Kishi K., Kramer S., Marshall J., Sandstrom A., 2019. 4 Facts About Religion in New Zealand. Pew
Research Center 21.03.2019. URL: https:// www.pewresearch.org/fact-tank/2019/03/21/4facts-about-religion-in-new-zealand.

Taylor D., 2017. Muslim Mother Takes Legal Action Against School Over Face Veil Ban. The Guardian. 21.07.2017. URL: https:// www.theguardian.com/world/2017/jul/20/ muslim-mother-takes-legal-action-againstschool-over-face-veil-ban.

The Changing Global Religious Landscape, 2017. Pew Research Center, April 5, 2017, The Changing Global Religious Landscape. URL: https:// www.pewforum.org/2017/04/05/the-changingglobal-religious-landscape.

The New Urban Agenda, 2016. The New Urban Agenda. Habitat III. The United Nations Conference on Housing and Sustainable Urban Development. 20.10.2016. URL: http://habitat3.org /the-new-urban-agenda.

The Rabat Plan: Challenging Hatred while Preserving Free Expression. 2013. IIMA Human Rights Office. 05.03.2013. URL: http://www.iimageneva.org/ the-rabat-plan-challenging-hatred-while.

The World Population Prospects: 2015 Revision. URL: https://www.un.org/en/development/desa/ publications/world-population-prospects-2015revision.html.

UN Climate Action Summit 2019. United Nations 23.09.2019. URL: https://www.un.org/en/ climatechange/un-climate-summit-2019.shtml.

World's Population Increasingly Urban with More than Half Living in Urban Areas. 2014. UN Search. 10.07.2014. URL: https://www.un.org/en/ development/desa/news/population/worldurbanization-prospects.html.

\section{Information About the Author}

Elena M. Miroshnikova, Doctor of Sciences (Philosophy), Professor, Chief Researcher, Research Center for Religious and Ethno-Political Studies, Leningrad State University named after A.S. Pushkin, Peterburgskoe Shosse St, 10, 196605 Saint Petersburg, Russian Federation, miroshnikovaem@gmail.com, https://orcid.org/0000-0002-3612-3016

\section{Информация об авторе}

Елена Михайловна Мирошникова, доктор философских наук, профессор, главный научный сотрудник Научно-исследовательского центра религиоведческих и этно-политических исследований, Ленинградский государственный университет им. А.С. Пушкина, Петербургское шоссе, 10, 196605 г. Санкт-Петербург, Российская Федерация, miroshnikovaem@gmail.com, https://orcid.org/0000-0002-3612-3016 